\title{
Knowledge Building and Mathematics: Shifting the Responsibility for Knowledge Advancement and Engagement
}

\section{La coélaboration de connaissances et les mathématiques : faire basculer la responsabilité pour l'avancement des connaissances vers l'apprenant} Joan Moss and Ruth Beatty

\author{
Authors \\ Joan Moss, Associate Professor (CSE/DPE), University of Toronto, OISE | Ontario \\ Institute for Studies in Education. Correspondence regarding this article can be sent to: \\ jmoss@oise.utoronto.ca \\ Ruth Beatty, Assistant Professor, Faculty of Education, Lakehead University.
}

\section{Abstract}

Three classrooms of Grade 4 students from different schools and diverse backgrounds collaborated in early algebra research to solve a series of linear and quadratic generalizing problems. Results revealed that high- and low-achieving students were able to solve problems of recognized difficulty. We discuss Knowledge Building principles and practices that fostered deep understanding and broad participation. Students used the online Knowledge Building environment Knowledge Forum ${ }^{\oplus}$ to conduct their work and we illustrate how Knowledge Forum supported a Knowledge Building culture for mathematical learning and problem solving. Analyses of participation patterns and note content revealed practices consistent with Knowledge Building principles, specifically democratization of knowledge, with students at all achievement levels participating, and epistemic agency, with students providing evidence and justification for conjectures and generating multiple solutions to challenging problems.

\section{Résumé}

Trois classes de quatrième année issues de diverses écoles et ayant des bagages de connaissance diversifiés ont participé à une recherche en algèbre élémentaire pour résoudre une série de problèmes linéaires et quadratiques généralisés. Les résultats ont démontré que tous les élèves, tant les moins performants que les plus performants, ont été en mesure de résoudre des problèmes complexes. L'article fait état des principes et des pratiques de coélaboration de connaissances qui mènent à une compréhension approfondie et à une participation élargie des élèves. Ces derniers ont utilisé l'environnement de coélaboration de connaissances en ligne Knowledge Forum ${ }^{\circledR}$ pour effectuer leur travail. Nous illustrons de quelle façon Knowledge Forum a soutenu une culture de coélaboration de connaissances dans l'apprentissage des mathématiques et 
la résolution de problèmes. Des analyses des modèles de participation et des contributions écrites des élèves ont révélé des pratiques cohérentes avec les principes de coélaboration de connaissances, en particulier la démocratisation de la connaissance (participation d'élèves à tous les niveaux de rendement) et l'action épistémique (élèves prouvant et justifiant leurs hypothèses et générant des solutions multiples aux défis proposés).

\section{Introduction}

We start by presenting a written discussion among Grade 4 students engaged in Knowledge Building in mathematics. The students were from different urban settings, they had never met each other, and they were collaborating online to find solutions to a series of challenging mathematics generalization problems. This work was part of an ongoing study of early algebra. A special feature of the research was that once the mathematics problems were posted on Knowledge Forum, the database was entirely student-managed; there was no teacher voice in the database and no answers provided from any source external to the students. Thus, it was the students who took the responsibility to offer conjectures, find solutions, and negotiate multiple approaches for mathematics problem solving. How was this possible? This report provides an overview of Knowledge Building pedagogy and technology that allowed students to assume high levels of agency for their knowledge work.

The Border Problem (see Figure 1) was one of six problems posted on Knowledge Forum. In this problem students were challenged to find the function, or "rule," ${ }^{1}$ to predict the number of border squares for any size of grid. As the reader will see in the protocol that follows, the students present two viable and different solutions based on different visual interpretations $^{2}$ - an area interpretation where the total area of the grid is calculated and the inner area is subtracted, symbolically, $y=x^{2}-(x-2)^{2}$, and a second strategy based on a perception of the border as four sides composed of $x$ number of squares $(4 x)$, with each side "sharing a square" $(-4)$, represented by $f(x)=4 x-4$. While we present formal symbolic notation to preview solutions that the students discuss, it must be noted that these young students had not had formal symbolic instruction ${ }^{3}$ but rather, in trying to communicate their mathematical ideas the students "invented" their own algebraic notation and combined this with natural language explanations, what Sfard (e.g., 1995) refers to as "syncopated" mathematical language.

\footnotetext{
${ }^{1}$ Students used the term "rule" throughout the intervention and at no time were taught or used the term "function".

${ }^{2}$ Over the course of the study the students developed five different viable solutions to the Perimeter Problem.

${ }^{3}$ Students had been introduced to function tables as part of an instructional sequence that preceded the problem solving on Knowledge Forum, and were familiar with the language of input number and output number. Over the course of the lesson sequence the students adopted the use of the letter $n$ to represent any number.
}

Knowledge Building and Mathematics: Shifting the Responsibility for Knowledge Advancement and Engagement 


\section{Border Problem}

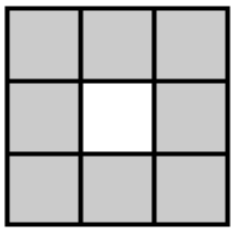

This is a $3 \times 3$ grid of squares with only the outside edge shaded.

If you had a $5 \times 5$ grid of squares where only the outside edge of squares is shaded, how many squares would be shaded?

If you had a $17 \times 17$ grid of squares with only the outside edge of squares shaded, how many squares would be shaded?

If you had a grid of $100 \times 100$ squares, how many would be shaded?

What is the rule? How do you know?

Figure 1: The Border Problem 
The discussion, which follows, involved students from all three classrooms, is taken verbatim from Knowledge Forum, and typifies the kinds of discourse that the students were engaged in as part of their mathematical problem solving.

The first note of this discussion $\left(\mathrm{HLab}^{4}\right)$, entitled Eureka!, was posted by a student, AW.

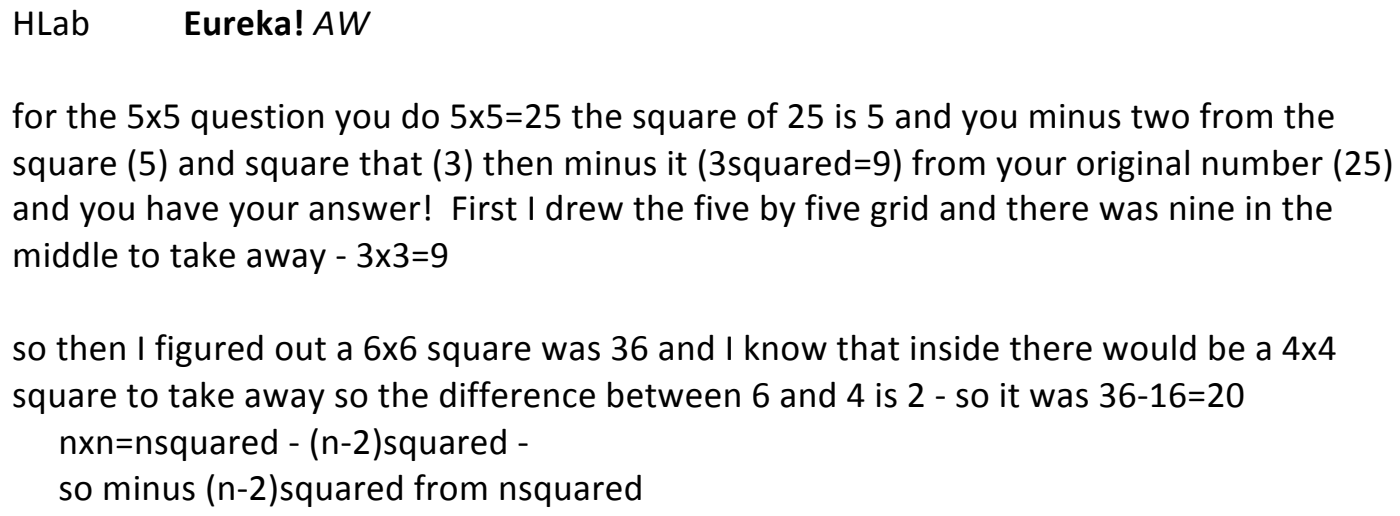

I agree with you and disagree with you because you've got the answer but in a complicated way. I disagree with you because there's an easier way than taking the square of 25 , subtracting 2 from it and square that and then subtract that from your original answer. I got the rule times $4-4$ because a square has 4 sides and you don't count the corners twice. I agree with you because for the first few questions you got it right.

Hlab

Two Ways AW

Why can't there be two ways. There are different ways to do lots of different problems I think you can have two ways $n \times n=n s q u a r e d-(n-2)$ squared - so minus $(n-2)$ squared from nsquared works and $\mathrm{x} 4-4$ works

\footnotetext{
${ }^{4}$ These codes are to indicate student author's classroom and achievement level, as elaborated below.
} 
This exchange is representative of the kinds of notes that the students wrote and discussions they were engaged in. Of note, as will be elaborated in further sections of this paper, is the difficult level of mathematics that the students were engaged in: generalizing problems are known to be difficult for much older students (e.g., Amit \& Neria, 2008; Becker \& Rivera, 2005; English \& Warren, 1998; Lee \& Wheeler, 1987; Orton \& Orton, 1994, 1999; Stacey, 1989; Stacey \& MacGregor, 1999; Warren, 2000, $2004,2005)$. Also of note, students were linked online with students in another school and veteran student knowledge builders were able to engage newcomers from a different school in Knowledge Building pedagogy and technology. Together they were able to sustain high level Knowledge Building discourse without a teacher serving as the facilitator or intervening to keep them motivated and focused. Students paid attention to and responded to one another; took on the roles of evidence-producers, moderators, and ratifiers; and negotiated the mathematical ideas developed - in this case, the possibility of multiple solutions for one problem, and the merits of each solution based on the elegance of the solution.

In this paper we present the context, methods and results from an experimental intervention to illuminate how Knowledge Forum, and the underlying Knowledge Building principles (Scardamalia, 2002, 2004) of democratization of knowledge and epistemic agency supported students in adopting a Knowledge Building culture for mathematical learning and problem solving.

\section{Background to the Research: Early Algebra}

For the last five years we have been working on a project in which we have been developing new learning contexts to support students in deep understanding of patterns and functions to introduce algebra across the grades (e.g., Beatty \& Moss, 2009, 2006a, 2006b; Moss \& Beatty, 2006a, 2006b; Moss, Beatty, Shillolo, \& Barkin, 2008; Moss \& McNab, in press). Pattern activities have become ubiquitous in reformoriented curriculum documents and mathematics textbooks as part of early algebra strands. The study of patterns, particularly those known as "generalizing problems," offers students a vehicle for understanding the dependent relations among quantities that underlie mathematical functions (e.g., Ferrini-Mundy, Lappan, \& Phillips, 1997; Lee, 1996; Mason, 1996; Mason, Graham, \& Johnston-Wilder, 2005; Steen, 1988) and also provides a rich context for generalizing (Pimm, 1995). Generalization and justification are both considered essential components of algebraic activity (Blanton \& Kaput, 2002; Carpenter \& Franke, 2001; Carpenter, Franke, \& Levi, 2003). Researchers argue that students should develop general connections early as a foundation for algebraic understanding, which has led to a wealth of studies focused on the promotion of generalizing activities (Blanton \& Kaput, 2002, 2004; Carpenter \& Franke, 2001; Schliemann, Carraher, \& Brizuela, 2001). Indeed, working with patterns and generalizing problems can provide a rich context for engaging students in the mathematical reasoning processes that are central to the internationally recognized standards of the National Council of Teachers of Mathematics (2000): problem solving, reasoning and

Knowledge Building and Mathematics: Shifting the Responsibility for Knowledge Advancement and Engagement 
proof, communication, connections (among mathematical topics and ideas), and use of multiple representations in generalizing and justification.

However, substantial evidence from past research suggests that understanding functions through pattern activities is challenging for students, and that "the route from perceiving 'patterns' to constructing algebraic representations is rather complex and fraught with potential problems for students" (Noss, Healy, \& Hoyles, 1997, p. 204; also see Kieran, 1992; Lee \& Wheeler, 1987). Although the study of patterns has the potential to develop the mathematical reasoning processes outlined by NCTM, the reality is that current instruction tends to reduce pattern lessons to superficial data driven pattern-spotting activities, which are grounded in arithmetic calculations (Bednarz, Kieran \& Lee, 1996). Students commit to their first conjectures of rules even in the face of invalidating data, and show little rigour or interest in supporting or justifying their conjectures (e.g., Lannin, 2005; Lee, 1996; Mason, 1996; Stacey, 1989).

Our research in students' learning of patterns has a double focus to address the findings and concerns in the literature. The first is the design of a sequence of instruction to provide students with multiple representations of functions-numeric, geometric and narrative - and promote a way of integrating these representations. This learning sequence is grounded in Case's theory of mathematical development and central conceptual structures (see Case \& Okamoto (1996) and Moss \& Case (1999) for a discussion of the general theory; and Moss, Donoahue, Eisenband, Shapiro, \& Macdonald (2004) for a discussion of application of this theory to pattern learning). The second focus of our research, and the goal for this paper, is to investigate the potential of Knowledge Building pedagogy and technology to provide support for students' developing understanding of patterns and functions. More specifically we test the possibility of young students' engagement in theory development in the context of mathematical problem solving.

We first discuss the Knowledge Building principles that guided our analyses: democratization of knowledge and epistemic agency. We then outline the methods used in the study. The results will be presented in terms of frequency counts of student participation, as well as verbatim accounts and analysis of student notes to provide evidence of Knowledge Building. We conclude with exploratory conjectures about Knowledge Building and mathematics.

\section{Knowledge Building, Knowledge Forum, and Mathematics Learning}

The creation of a Knowledge Building community supported by Knowledge Forum in elementary classrooms has been shown to foster an inquiry-based, theory development orientation to work in various domains (McAuley, 2009; Resendes \& Chuy, 2010; Scardamalia, Bereiter, Chuy, Prinsen, Resendes, \& Teplovs, 2010; Scardamalia, Bereiter, Hewitt, \& Webb, 1996; Zhang, Scardamalia, Reeve, \& Messina, 2009). To date the use of Knowledge Forum in mathematics education has been limited (Hurme \& Jarvela, 2005; Nason \& Woodruff, 2002), particularly at the elementary school level.

Knowledge Building and Mathematics: Shifting the Responsibility for Knowledge Advancement and Engagement 
Two concerns have been raised about the applicability of Knowledge Forum for typical school-based mathematics learning. First, school-based mathematical problems typically lack open-endedness and authenticity, thus limiting the need for theory development (Nason \& Woodruff, 2002). The second concern was that Knowledge Forum is a textbased discourse space, and did not support symbolic math representations to aid communication. ${ }^{5}$ Our conjecture was that Knowledge Forum would provide an authentic context for collaborative problem solving and extended mathematical discussions while students worked on open-ended school-based generalizing problems. With respect to the text-based nature of Knowledge Forum, researchers suggest that verbal and written communication of mathematic ideas is essential to support development of an understanding of structure (e.g., Pugalee, 2001) and is a necessary step in moving towards symbolic representations. Thus we were interested in investigating how students would communicate their mathematical ideas in written discourse conducted in a text-based environment. Additionally Knowledge Forum supports graphical representation of ideas, a feature that facilitates work with patterns.

We also investigated patterns of participation through Knowledge Forum to assess the extent to which a Knowledge Building culture in mathematics was developing similar to results reported in other domains such as science and social science (e.g., Bereiter \& Scardamalia, 1989, 2003; Scardamalia, Bereiter, Hewitt, \& Webb, 1996). Specifically for this study, we wanted to determine if students, given the opportunity to engage in mathematical problem solving on Knowledge Forum, would reveal evidence of core Knowledge Building principles: democratization of knowledge and epistemic agency. The scope of this paper does not allow a full discussion of the principles that underlie Knowledge Building and Knowledge Forum ${ }^{6}$, but rather how these two serve the central mathematical goals of the project.

\section{Democratization of knowledge}

In most mathematic classrooms, even with the best of intentions, there is an imbalance in students' participation levels. One reason for this is that there is often a hierarchy of students' mathematical achievement and status. The contributions from students who are perceived to be "higher" are generally accepted and acknowledged much more readily than those of weaker students whose ideas can be discounted or ignored. In addition, in most math classrooms the teacher is the expert and sole source of knowledge. In a Knowledge Building community, however, the principle of democratization of knowledge supports the notion that all contributions are valued and can be improved. Democratization of knowledge can perhaps be achieved more readily through the absence of the teacher's voice in the database, in the sense that students themselves then need to work harder to provide explanations and they don't look to the teacher to provide "the answer." As part of our analyses we looked at the participation

\footnotetext{
${ }^{5}$ Open source developments will make it possible to incorporate symbolic math representations and expand Knowledge Forum functionality.

${ }^{6}$ Please see Scardamalia and Bereiter, present issue.
}

Knowledge Building and Mathematics: Shifting the Responsibility for Knowledge Advancement and Engagement 
patterns for both high and low achieving students to determine whether all students were contributing ideas and accessing the ideas of others in meaningful ways.

\section{Epistemic agency}

The emphasis on student agency and the centrality of student ideas was a fundamental reason for incorporating Knowledge Forum in our study. Bereiter and Scardamalia (e.g., Bereiter, 2002; Scardamalia, 2002 ) use the term epistemic agency to characterize the responsibility that the group assumes for the ownership of ideas that are given a public life in Knowledge Forum. The principle of epistemic agency, therefore, underpins other Knowledge Building principles such as idea improvement and the democratization of knowledge. The students themselves take on the responsibility of contributing ideas, monitoring one another's contributions, and asking for clarification and revisions with an eye towards moving the theorizing forward. As has been well documented, in traditional mathematics classrooms students do not see themselves in the role of initiators of mathematical ideas or theories, and even less as leaders in relation to developing mathematical discourse. The teacher and textbook are the authorities and students do not see mathematics as a subject to be created or explored. We wondered if a shift in responsibility would result in an increase in students' engagement in the language of and disposition for mathematical discourse. We looked for evidence of epistemic agency through an analysis of the extent to which students were responding to one another's ideas. We also looked for examples of student discussions that moved the mathematical content knowledge forward.

\section{Methods}

\section{Participants}

Participants were students from three different Grade 4 classrooms (8-9 year olds), $\mathrm{n}=68$. One of the classrooms was a University Laboratory school and the other two classrooms were in an inner city public school serving an at-risk population (high ESL, low SES) that has been designated as the third neediest school in the school board. Prior to the study, none of the students in these classrooms had been exposed to any kind of work with mathematical functions, nor had they had any formal instruction in symbolic representations of algebraic functions. The 22 students from the laboratory school had used Knowledge Forum as part of their science curriculum, as had half of the students from the public school, and so they were familiar with the software and processes. Those who had not used Knowledge Forum previously had two lessons in how to use the software, and another lesson to work with an experienced peer. All students were shown how to open views, compose and contribute notes, and how to respond to other students' contributions. None of the students had worked on Knowledge Forum for mathematical problem solving.

\section{Procedures}

The intervention began with an instructional sequence of twelve 45-minute lessons

Knowledge Building and Mathematics: Shifting the Responsibility for Knowledge Advancement and Engagement 
designed to develop an understanding of linear functional relationships. Prior to entering into the lesson sequence, the students were told that at the end of the patterning unit they would be linked with students from a different school on Knowledge Forum in order to work together to solve very difficult problems. The lesson sequence was comprised of activities involving numeric patterns, guess my rule games, geometric growing sequences with position cards and specially created word problems. For a detailed outline of this sequence please see Moss and Beatty (2006a; 2006b). As mentioned previously, at no time were the students taught any formal algebraic notation. After completing the instructional sequence, students from the three classrooms were linked electronically and invited to collaborate in solving six generalizing problems.

For each problem, students were asked to discern a functional relationship between two sets of data and express this as a "rule," and to explain their reasoning. Each problem was posted on a separate Knowledge Forum "view." There were three pairs of problems, which were matched for structural similarity and increasing difficulty. The first two problems (The Cube Sticker and the Trapezoid Table -see the Appendix for a full description of each problem) both had an underlying functional rule of $y=m x+b$, (where $\mathrm{m}$ and $\mathrm{b}$ were positive integers). The second two problems (The Border Problem and the Triangle Dot Problem) had an underlying function of $y=m x-b$. The final two problems (The Handshake Problem and the Pattern Kingdom) were based on the quadratic function, $\left(x^{2}-x\right) / 2$, which posed an unfamiliar challenge to the students since they had previously worked only with linear functions. The Knowledge Forum database was available to students over an eight-week period, and on average each student had approximately 30 to 45 minutes per week to work on-line. The time that the students had to work on the database varied depending on the classroom and the availability of computers, and was usually carried out during one math period a week. In this study the site for problem solving was the Knowledge Forum database with a focus on peer collaboration with students from all classrooms. Consequently, there were few whole class discussions related to student problem solving. ${ }^{7}$

\section{Data sources}

The data for the present study comes from the 247 notes that the students in the three classes posted in response to the six generalizing problems. As part of the larger study, the students from the three classrooms were assigned to a level of mathematical achievement (high, medium, or low) based on teacher rating of general mathematics performance and report cards.

For this study, each note was given a code based on the student author's classroom (Lab = Lab School, PS1 = public school classroom 1, PS2 = public school classroom 2), and

\footnotetext{
${ }^{7}$ We have subsequently carried out a study in which we included Knowledge Building whole class discussions as part of the intervention. See Beatty and Moss, 2009.
}

Knowledge Building and Mathematics: Shifting the Responsibility for Knowledge Advancement and Engagement 
their achievement level $(\mathrm{H}, \mathrm{M}$ or $\mathrm{L})$. All notes were given a title, indicated by bold text, by the student or students who posted them. Authorship is indicated by the student's first and last initial. Any metacognitive scaffolds ${ }^{8}$ are indicated through the use of italics.

Each note was read by the researcher and one or more research assistants, and coded for type of note (i.e., original notes or notes that were in response to original notes) and for mathematical content. We analyzed notes and discussions to determine the extent to which the principles of democratization of knowledge and epistemic agency were exemplified.

\section{Results}

The intention of this paper is to present evidence of the Knowledge Building principles, in particular democratization of knowledge and epistemic agency. Thus, the results are presented in two major sections to reflect the Knowledge Building principles that are the focus of this study. ${ }^{9}$

\section{Results - Democratization of Knowledge}

There is always a question in collaborative learning situations about the usefulness of collaborative learning for students of varying abilities. This study involved a very diverse population of students in terms of ability level and so we were interested to learn about the kinds of contributions made to the database as a function of ability level.

We compared the contributions of high-achieving students to their lower achieving peers in terms of whether their notes were original ideas or written in response to the ideas of others. We found that $70 \%$ of notes posted by lower-achieving students were in response to notes of other students, compared to $54 \%$ of notes posted by higherachieving students. This finding indicates that lower-achieving students spent a greater proportion of their time on Knowledge Forum reading and responding to the ideas of other students than their higher-achieving peers.

It has been suggested that in many collaborative learning situations collaboration may benefit lower-achieving students only in as much as they can copy the ideas of more advanced students, and that this copying may not necessarily lead to an increased understanding (Steffe, personal communication, October 2005). When we looked specifically at the content of the notes posted by lower-achieving students in response to those of higher-achieving students, we discovered that, contrary to the concerns stated above, when lower-achieving students read and built onto the theories of higher-

\footnotetext{
${ }^{8}$ Metacognitive scaffolds in Knowledge Forum are optional and customizable supports to encourage students to engage in high-level knowledge processes such as theory building while they write notes (Scardamalia 2003). The scaffolds used in this study include my theory, I need to understand, new information, a better theory, and putting our knowledge together.

${ }^{9}$ For an analysis of frequency counts of the content of students' notes, please see Moss and Beatty, 2006a.
}

Knowledge Building and Mathematics: Shifting the Responsibility for Knowledge Advancement and Engagement 
achieving students, they did so by translating the ideas of others into modified representations. This indicated that they were not just repeating the ideas of others but were incorporating these ideas into their own understanding using language, drawings, and other representations that were meaningful to them.

In the following note, a middle achieving student, SG, offers a solution to the border problem based on his understanding of the numeric operations that yield the correct output numbers (shaded squares) from the input numbers (type of square grid). His explanation of his rule includes an understanding that the rule is to predict the border, "only count the edge," of each grid and that the corners overlap.

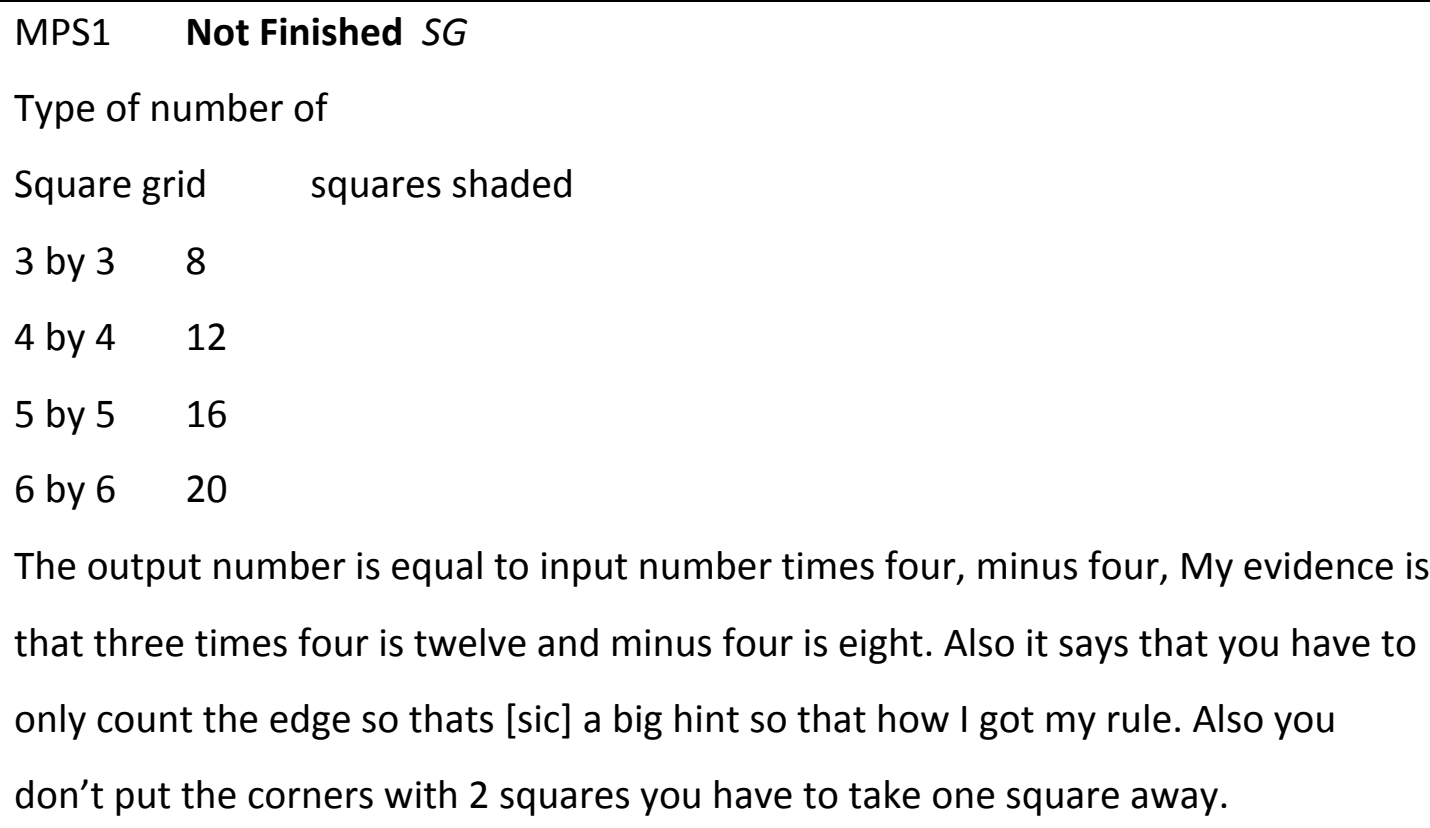

In response, a lower achieving student responds by outlining his own initial "goldilocks strategy" using guess-and-check. He then tried SG's offered rule on all the grids and agrees that the rule is "a perfect fit". Although JC may not understand the reasoning behind the rule in the same way that SG does, he does seem to grasp that SG's solution is a rule because it works for all instances.

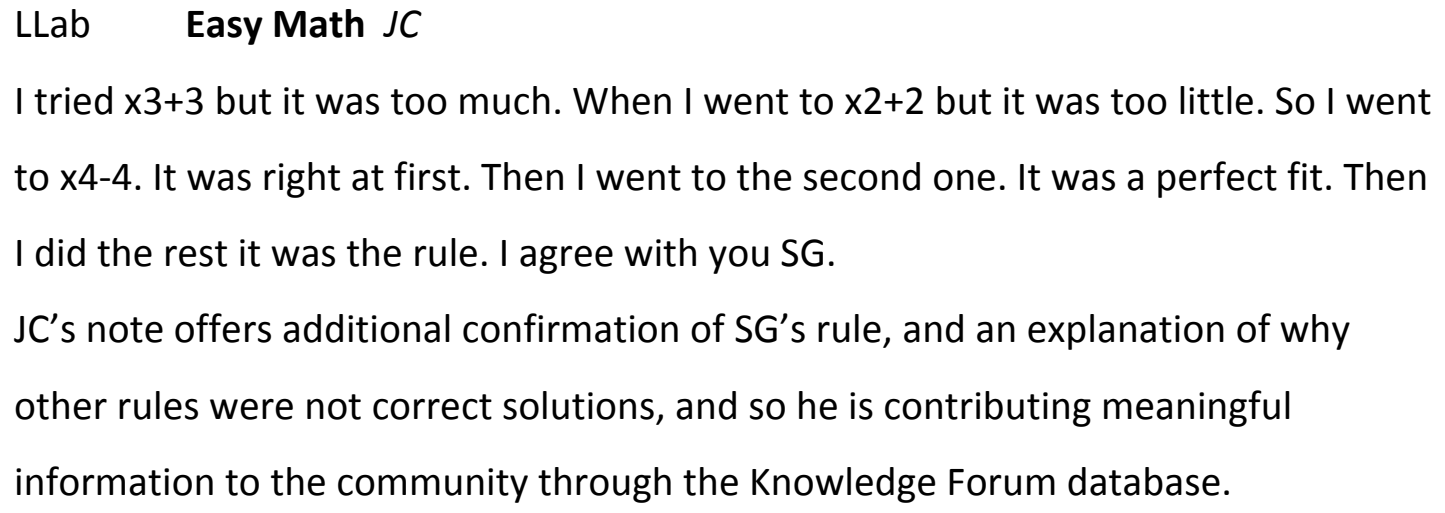


Lower-achieving students were also able to use their reinterpretations to critique the solutions of higher-achieving students, as illustrated in the following example. MB, a higher-achieving student, presents his solution to the Border Problem. SJ, a lowerachieving student, outlines his strategy for solving the problem, and is able to correct a calculation mistake in MB's note.

\section{HPS2 My Solution MB}

My theory is that 16 squares would be shaded in a $5 \times 5$ grid. 54 squares would be shaded in a $17 \times 17$ grid. 396 squares would be shaded in a 100x100 grid. Yes there is a rule and the rule is $\times 4-4$. We know that there are 4 sides to a square, so whatever the grid is you times the side by 4 . But the corners overlap, so that means -4 . Our evidence is that we tried it for each grid and it matched the correct number of shaded squares.

LPS1 $17 \times 17$ SJ

I agree with you because the $5 \times 5$ square is right because $5 \times 4-4=16$. I disagree with you because the $17 \times 17$ answer is wrong. My evidence is that the rule is $\times 4-4$ so 17x4=68-4=64. I know this is the rule because I have a t-chart and it says this: 3 will be 8,4 will be 12 and 5 will be 16 . If you use this rule you will get the answer to the question.

In the preceding example, a lower-achieving student was able to incorporate a solution presented by a higher-achieving peer and then reinterpreted the solution using a different representation ( $t$-chart). Whereas MB derived a solution based on the geometric structure of the problem, SJ indicates that he had constructed a table of values to support his understanding of the rule.

In this next example, a higher achieving student, NS, posted a solution to the problem based on a numeric analysis of the data given, with the conclusion that only the operations of x4-4 would lead to the correct output numbers. She states that her rule would apply for all the other numbers, but is unclear as to why this is true. In a revision to her original note, for which she uses the scaffold "a better theory", NS contributed an addition to her idea that includes a more conceptual orientation to the problem structure. 


\section{PS1H Relationships NS}

My theory is that the Output \# is = to the input \# times $4-4$. My evidence is that $3 \times 4=12$ and -4 is 8 which is the output. You need to multiply the input $x 4$ [only one side] because without multiplying you wouldn't get 12 . Then when you minus another \# besides 4 the output wouldn't be 8 . The same rule applies for all the other numbers. Like: $100 \times 4=400-4=396 \quad 10 \times 4=40-4=36 \quad 14 \times 4=56-4=52$

I think I still have to think a little more to explain my theory.

\section{A better theory}

You need to $\times 4$ because you need 4 sides to make a square. Like $3 \times 3$ means 3 is the length and the other 3 is the width so one length or width $\times 4=$ to the whole border.

In response to NS's note, two lower achieving students respond by providing clarifications to NS's note. In the first response ALe, who understands that the rule is $\mathrm{x4-}$ 4 , restates NS's rule to make sure that she (and others reading the note) are not confused. CW also asks for clarification based on his knowledge of multiplication facts.

\section{LabL I agree Ale}

I agree with you because As long as you don't get confused because they might think that you have to $x$ the number when times the number by four and then minus four. What your [sic] saying here is that you don't $x$ the number by itself. Instead you times it by four then minus four, As long as you don't get confused I completely agree with you.

\section{LabL Can you be a bit more clear CW}

Can you be a bit more clear because it says $3 \times 3=8$ and your [sic] saying $3 \times 4=8$.

In response, NS clarified her reasoning by stating that it is the length or width of a grid that is multiplied by 4 because of the four sides of the grid.

\section{PS1H Meaning it NS}

I meant to say in my note that one length or wideth [sic] which is the same in this case. Then take the length or wideth [sic] then $\mathrm{X}$ by 4 because there are 4 sides. 
When we looked at the activity in the database of lower- and higher-achieving students it was encouraging that the lower-achieving students appeared to be utilizing the ideas posted by their higher-achieving peers to move their own learning forward, and were offering their own ideas or reinterpretations of ideas as participating members of the Knowledge Building community.

\section{Results - Epistemic Agency}

In Knowledge Building communities members make progress not only in improving their personal knowledge, but also in developing collective knowledge through progressive discourse (Bereiter \& Scardamalia, 2003). As mentioned in the previous section, there were many instances of students making concerted efforts to move the understanding of the group forward as they read and responded to each other's contributions and built onto the ideas of others rather than simply posting individual ideas. Also, many of the discussions revealed students' commitment to include broader issues of mathematical understanding.

The following discussion comes from the Handshake Problem. This problem, which has been shown to be difficult for much older students (e.g., Cooper \& Sakane, 1986), requires that students find the quadratic rule to determine how many handshakes there would be if everyone shook hands with everyone else in any size group. Initially many students came up with a recursive numeric pattern, as the first note exemplifies. However, in contrast to findings of other research with older students (e.g., Lannin, 2005; Steele, 2005; Steele \& Johanning, 2004) a number of notes were posted by students who realized the limitations of this recursive approach, and questioned one another as to how to find the explicit functional rule. As $M$ and J state in their note, "the thing about math is to figure out the fastest and most accurate way to do things." 


\section{MPS1 Follow the Next Output Number $T H$}

If there is [sic] 3 people there are 3 handshakes. If there is [sic] 4 people there are 6 handshakes. So I think that it is like $2+1=3$ that is the next handshake output. So $3+3=6$ that is the next handshake. My rule will be the input+output=next output. Number of people Number of handshakes

1

3

6

10

MLab M and J's Theory MT

I was wondering could you do this rule for 149378 people? Because the thing is in our theory you have to know the number of handshakes before the one you're doing...but the large numbers are so big it would take forever to figure it out! The thing about math is to figure out the fastest and most accurate way to do things.

MPS2 I need to Understand VT

I need to understand if there is another way to get the answer? I want to solve how many handshakes would 10 people do without making a T-chart.

\section{HPS1 Thinking SI}

My theory is that the rule is the number $\mathrm{x}$ the number -1 divided by 2 . I think that it is the number $x$ the number -1 because a person can shake with the number of people 1 less than the person because the person cannot shake with his or herself. It is divided by 2 because 2 people make a handshake.

These notes show a disposition in these students to move mathematical reasoning forward. First of all, based on the literature, it is well known that one of the difficulties in generalizing problems lies in the propensity of students and adults to use a recursive strategy - a focus on the variation within a single set of data rather than on the

Knowledge Building and Mathematics: Shifting the Responsibility for Knowledge Advancement and Engagement 
relationship between two data sets-for identifying and describing generalizations (e.g., English \& Warren 1998; Lee 1996; Orton 1997; Warren, 2000, 2005). While recursive strategies allow students to predict what comes in the next couple of positions of a series, it does not foster the ability to perceive the (structural) relationship across the two data sets to find the underlying rule. However, these students, having found a numeric pattern based on recursion, are dissatisfied with this as the sole solution. We see a push to go beyond spotting the numeric pattern, which the students see as a serious limitation because "you have to know the number of handshakes before the one you're doing." The students persist to find and understand both the underlying mathematical structure of the problem and the articulation of this as a rule. In our view, while there is no straightforward way to identify epistemic agency, this kind of interest in expanding the status of the understanding that we have seen in this particular set of notes can be taken as evidence of epistemic agency.

\section{Summary of Results}

\section{Knowledge Building principles in evidence}

Throughout the database we found evidence of practice consistent with two core Knowledge Building principles: democratization of knowledge and epistemic agency. Democratization of knowledge was evidenced by participation of students at all levels. It was not only the higher-achieving students who were motivated and interested in solving these difficult problems; the lower-achieving students used the opportunity provided by Knowledge Forum to look at solutions posted by their peers, and were able to incorporate these ideas into their own solutions at a level that was meaningful for them. A particularly encouraging result of this study was the number of notes posted by lower-achieving students as these students rarely spoke out in class and had been silent members of the mathematics community of the classroom. As our analyses revealed, these lower-achieving students posted proportionally more notes in response to the ideas of other students, rather than original ideas, and were clearly engaged in collaborative discourse. We believe that a Knowledge Building approach increased the access to ideas and the means to work with them for students identified as "lowachieving." These students were able to engage with the mathematical ideas presented, and their contributions were acknowledged by higher-achieving peers. Also, we believe that because students from the two participating schools had never met, that the status hierarchies with respect to mathematical prowess were leveled, so that the contributions of all students were equally considered.

Epistemic agency was seen in students' working together to solve these problems and to support each others' suppositions or question one another's incorrect solutions so that the group as a whole could achieve a level of assurance about whether the answers being offered were correct solutions for the problems. This was necessary because, as previously stated, neither the teachers nor the researchers ever commented on any of the answers offered (on or off Knowledge Forum) so the students had no external source of information as a means of checking whether the solutions posted were "right"

Knowledge Building and Mathematics: Shifting the Responsibility for Knowledge Advancement and Engagement 
or "wrong." This is a most interesting finding, as in most Knowledge Building contexts the teacher is more engaged in the online exchanges (see, for example, Brett, Forrester, \& Fujita, 2009; MacKinnon \& Aylward, 2009; Sun, Zhang, \& Scardamalia, present issue). It is especially interesting that left to their own devices the students developed a disposition for offering not just solutions for problems, but took the responsibility to offer evidence and justifications for their solutions with the intention of making their understanding comprehensible to everyone. In this student-managed database the discussions broadened to include such themes as the elegance of explicit functions, recursive numeric patterns, and the possibility of multiple solutions for problems.

\section{Discussion}

Generalizing problems are now common in textbooks in many countries to serve as a foundation for mathematical functions (Lee, 1996; Mason; 1996; Zazkis \& Liljedahl, 2002) and for supporting justifications as an introduction to algebraic reasoning (Lee \& Wheeler, 1987; Radford, 1999, 2003, 2006). However it has been shown that, at least given traditional instruction, students' approach to generalizing and justifying through patterning problems is limited. When we analyzed the contributions that students made on Knowledge Forum we found a very different pattern of problem solving - a pattern especially impressive for such young students from such diverse backgrounds. Not only were they able to find multiple solutions to very challenging generalizing problems, ${ }^{10}$ but also the notes that they contributed to the database showed a commitment to providing explanations and evidence for conjectures and rules. This clarity of communication and justification, while central to new reform efforts, eludes much older students. As our data revealed, the students' problem solving strategies were not limited to the simple recursive strategies that typify the reasoning for these kinds of generalizing problems; but rather, they found multiple functional rules that allowed them to make predictions for instances of the pattern in any position, indicating an ability to generalize (Mason, 1996) their rules from particular instances.

The students in these classrooms had no experience prior to this study with these kinds of problems, as indicated by low performance on pretests. In addition, interviews with students at the beginning of the study revealed that student responses to problems of this sort were limited, and involved "guess and check" or recursive reasoning. While the intervention that preceded the Knowledge Forum problem solving was designed to provide students with grounding in linear functions of the form $y=m x+b$, the kinds of problems that they encountered on the database were substantially more difficult. The Knowledge Forum problems included two linear problems of the form $y=m x-b$, and two problems based on quadratic functions $\left(x^{2}-x\right) / 2$, which the students had not learned. In

\footnotetext{
${ }^{10}$ While the scope of this paper allowed for an analysis or presentation of students' problem solving for only two of the six problems posted, these kinds of strategies typify the students' problem solving for all six problems.
}

Knowledge Building and Mathematics: Shifting the Responsibility for Knowledge Advancement and Engagement 
addition, these problems required the students to ascertain the independent and dependent variables, as well as the relationship between the two.

We believe that our research results, as outlined in the previous section, indicate that the students in our study were engaged in Knowledge Building. Thus we speculate that Knowledge Building as supported by Knowledge Forum played a significant role in the students' mathematical achievements.

At the most basic level we see the attributes of the software itself as contributing to the outcomes of this study. The visual set up of the Knowledge Forum views allows students to trace their contributions and to review discussions. As students contribute and respond to one another, their notes are automatically linked, and the resulting webs provide a visually based ongoing record of the development of increasingly sophisticated ideas. Students can see the evolving problem solving space that represents the growing complexity of discussions.

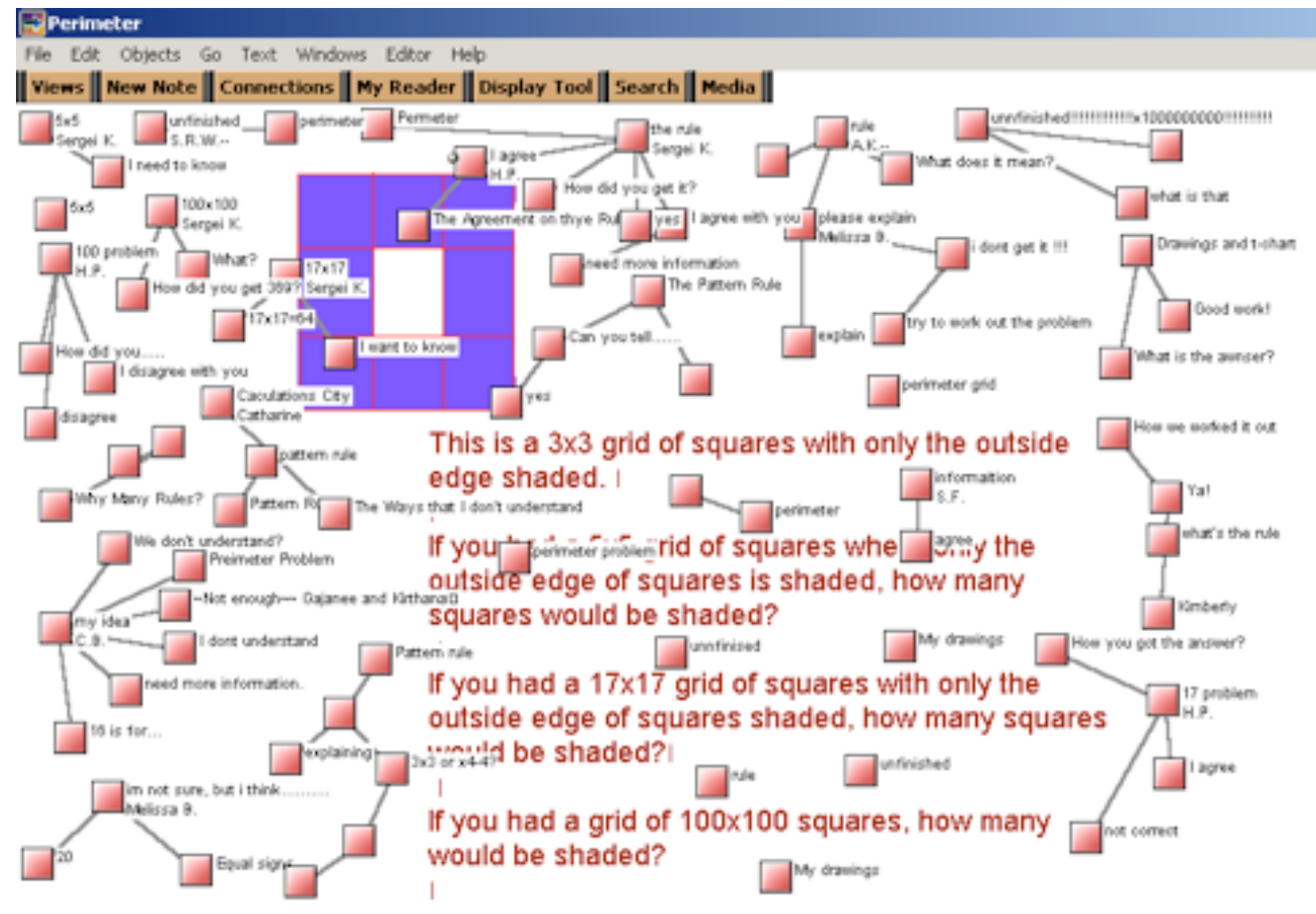

Figure 2: Border Problem View

More importantly, we believe that in this study Knowledge Forum was a tool that allowed for learning consistent with Knowledge Building principles. Knowledge Forum gives students' ideas a space in which to reside that is accessible to everyone. The ability to record ideas, coupled with the asynchronicity of the discussion, provided students with both the software capability and the think-time to revisit their original solutions in 
order to broaden and refine their own ideas, and to extend the ideas of others. In our study, we elected to have Knowledge Forum operate as a student-managed database. This turnover of responsibility appeared to result in the students' impressive perseverance while working on these school-based problems, in order to contribute meaningful ideas. Student ownership meant that the mathematical knowledge for solving these problems did not reside with the teacher or in textbooks, but in the form of student contributions. The generalizing problems were novel, of a high level of difficulty, and required the negotiation of different perspectives. Everyone's ideas and contributions were considered. Students took on the responsibility of developing ideas, pushing for idea improvement, and managing their own learning, which is evidenced by the development of a community norm of offering evidence and justifications so that all ideas were comprehensible to everyone. This commitment to finding solutions, negotiating multiple solutions, and articulating justifications for conjectures meant that these students were able to work at a higher level of mathematics than has been previously shown. We believe that a focus on contributing to the community knowledge base of strategies, solutions and justifications, allowed these students to succeed beyond expectations.

\section{Shifting the responsibility for learning and engagement}

The context of our work in Knowledge Building and mathematics is located in the reform vision for mathematics learning (e.g., Kilpatrick, Swafford, \& Findell, 2001; Ontario Ministry of Education and Training, 2005; NCTM, 2000). Since 1989, when the National Council of Teachers of Mathematics produced the first set of standards of practice for mathematics teaching, there has been a growing effort to change mathematics teaching and learning practices as part of a reform vision for mathematics education. Central to this vision is a shift from classrooms as simply a collection of individuals towards classrooms as mathematical communities of collaboration and inquiry (NCTM, 2000). In line with this reform vision, scholars and reformers have been advocating for new social practices that significantly alter traditional discourse patterns in classrooms. This has led to the adoption of new classroom social cultural norms (Cobb, Woods, \& Yackel, 1993) such as communities of learners that emphasize classroom discourse grounded in the spirit of the discipline of mathematics. One of the central precepts underlying the establishment of the community of learners is the importance of discourse and disagreement in individual knowledge growth (Lampert, 1990; Lampert, Rittenhouse, \& Crumbaugh, 1998).

An important feature of the Knowledge Building community model supported in the current research is support for community knowledge and for students to engage in the reasoning processes central to the NCTM process standards: specifically, making conjectures, abstracting mathematical properties, explaining reasoning, validating their assertions, and engaging in discussions and questions regarding their own thinking and the thinking of others. It has been noted that these kinds of reasoning patterns, with 
their rigorous attention to evidence and justification, are not easily achieved (Jacobs, Hiebert, Bogard Givvin, Hollingsworth, Garnier, \& Wearne, 2006) .

Over the course of our research in Knowledge Building and mathematics our data repeatedly revealed that intellectual efforts marked by justification and evidences are central to the reasoning of the students. However, while the kinds of mathematical behaviours that take place are similar across the two discourse structures, there also appear to be differences between the Knowledge Building communities and community of learners model that we believe are worth exploring. Clearly both are communities where learning is taking place. Clearly, both approaches support principles such as idea improvement, epistemic agency and democratization of knowledge. However it has been suggested that not all communities of learners are communities of knowledge builders (Scardamalia, 2002). Taking this thought further, it is legitimate to ask if there are important or even fundamental differences between "communities of learners," and the Knowledge Building approach underpinned by Knowledge Forum (see, for example, Scardamalia \& Bereiter, 2007).

\section{Some thoughts on communities of learners and Knowledge Building communities supported by Knowledge Forum}

In writing about the characteristics of learners in community of learner classrooms, Lampert et al. (1998) conclude that

In order to be judged as successful learners of mathematics in this kind of classroom, the students need to demonstrate that they are making conjectures about the mathematics they are engaged in and justifying those conjectures with logic and mathematical evidence considering reasonableness of the assertions made by others who seem to disagree and ultimately reasoning collaboratively toward their conclusions. (p. 736)

One way of interpreting this statement, with its focus on processes of conjecturing, justifying and using evidence, is that participants in communities of learners see their role as gaining expertise in providing justifications and critiquing the ideas of others. In contrast, the students who have participated in the mathematics Knowledge Building research appear to have a different focus or understanding of the purposes of the enterprise.

In our analyses of the data collected over the three years of our studies, we noted that students who are engaged in Knowledge Building and online discourse favoring theory development spend less time justifying and critiquing than engaging in collaborative efforts to produce new ideas, new theories and new solutions to very difficult problems. While these students, like those in the community of learners, did provide evidence and justification, the data suggest that this was done in the service of the production of new ideas. This seems to us to point to the possibility of two different discourse structures 
and cultures of engagement for community of learners and Knowledge Building communities.

\section{Different culture of engagement - shifting the responsibility and democratizing the process}

We have found in our work with students, that the culture of Knowledge Building and Knowledge Forum has allowed for and fostered diverse kinds of intellectual efforts from very diverse populations of students. In Knowledge Building communities, "democratization" implies more than the legitimization of individual ideas, but an understanding that Knowledge Building requires multiple voices and perspectives, even early, not-very-well-worked-out perspectives, in order to break new ground and continuously produce new knowledge to extend current understanding. In this investigation students worked as a collective to contribute ideas to their evolving understanding of important math ideas and to find multiple solutions to the problems posted.

We end this paper with reflections ${ }^{11}$ from two students. To us they convey how students in our research projects understand their responsibilities in the development of new mathematical understanding. The first quote is from a student for whom working on Knowledge Forum and Knowledge Building was already an established practice. The second is from a student for whom the work reported in this paper was the first Knowledge Building/Knowledge Forum experience.

Each time we solved a problem, afterwards we read other people's notes and tried to improve them by asking them questions. And from some notes we really learned some more because we found the rule, we didn't always know which part of the rule represents what, so we asked other people and they had different ideas than us and that was really interesting.

It was good to use the computer because, like, if you have a theory and you place the theory on Knowledge Forum then people can read the theory and maybe they will know something about the rule or an idea and they can build onto your theory. Also you can even change your theory and you can agree and disagree with other people.

\section{References}

Amit, M. \& Neria, D. (2008). "Rising to challenge": Using generalization in pattern problems to unearth the algebraic skills of talented pre-algebra students. ZDM Mathematics Education, 40, 111-129.

\footnotetext{
${ }^{11}$ These two student quotes, typical of the common sentiment, came from a classroom discussion in which participating students reflected on their experiences of Knowledge Building and mathematics.

Knowledge Building and Mathematics: Shifting the Responsibility for Knowledge Advancement and Engagement
} 
Beatty, R., \& Moss, J. (2006a). Connecting grade 4 students from diverse urban classrooms: virtual collaboration to solve generalizing problems. In C. Hoyles \& J. Lagrange (Eds.), Proceedings of the Seventeenth ICMI Study: Technology Revisited. Hanoi, Vietnam.

Beatty, R., \& Moss, J. (2006b). Multiple vs numeric approaches to developing functional understanding through patterns-affordances and limitations for grade 4 students. In S. Alatorre, J.L. Cortina, M. Sáiz, \& A. Méndez (Eds.), Proceedings of the 28th Annual Meeting of the North American Chapter of the International Group for the Psychology of Mathematics Education. Mérida, México: Universidad Pedagógica Nacional.

Beatty, R., \& Moss, J. (2009, April). "I think for every problem you can solve it...for every pattern there is a rule"1: Tracking young students' developing abilities to generalize in the context of patterning problems. Paper presented at the Annual Meeting of the American Educational Research Association, San Diego, USA.

Becker, J.R., \& Rivera, F. (2005). Generalizing strategies of beginning high school algebra students. In H.L. Chick, \& J.L. Vincent (Eds.), Proceedings of the 29th Conference of the International Group for the Psychology of Mathematics Education (Vol. 4, pp. 121-128). Melbourne: PME.

Bednarz, N, Kieran, C., \& Lee, L. (1996). Approaches to algebra: Perspectives for research and teaching. In N. Bednarz, C. Kieran \& L. Lee (Eds.), Approaches to Algebra: Perspectives for research and teaching (pp. 3-12). Dordrecht: Kluwer Academic Publishers.

Bereiter, C. (2002). Education and mind in the knowledge age. Mahwah, NJ: Lawrence Erlbaum Associates.

Bereiter, C., \& Scardamalia, M. (1989). Intentional learning as a goal of instruction. In L. B. Resnick (Ed.), Knowing, learning, and instruction: Essays in honor of Robert Glaser (pp. 361-392). Hillsdale, NJ: Lawrence Erlbaum Associates.

Bereiter, C., \& Scardamalia, M. (2003). Learning to work creatively with knowledge. In E. De Corte, L. Verschaffel, N. Entwistle, \& J. van Merriënboer (Eds.), Powerful learning environments: Unravelling basic components and dimensions. (Advances in Learning and Instruction Series). Oxford, UK: Elsevier Science.

Blanton, M., \& Kaput, J. (2002, April). Developing elementary teachers' algebra "eyes and ears": Understanding characteristics of professional development that promote generative and self-sustaining change in teacher practice. Paper presented at the Annual Meeting of the American Educational Research Association, New Orleans, LA.

Knowledge Building and Mathematics: Shifting the Responsibility for Knowledge Advancement and Engagement 
Blanton, M., \& Kaput, J. (2004). Elementary grades students' capacity for functional thinking. In M. Jonsen Hoines, \& A. Fuglestad (Eds.), Proceedings of the 28th Conference of the International Group for the Psychology of Mathematics Education (Vol. 2, pp. 135-142).

Brett, C., Forrester, B., \& Fujita, N. (2009). Online learning journals as an instructional and self-assessement tool for epistemological growth. Journal of Learning and Technology, 35(1), Online: http://www.cjlt.ca/index.php/cjlt/article/view/517.

Carpenter, T. P., \& Franke, M. (2001). Developing algebraic reasoning in the elementary grades: Generalization and proof. In H. Chick, K. Stacey, J. Vincent, \& J. Vincent (Eds.), Proceedings of the 12th ICMI Study Conference (vol. 1, pp. 155-162). Melbourne: Department of Science and Mathematics Education, The University of Melbourne.

Carpenter, T.P., Franke, M., \& Levi, L., (2003). Thinking mathematically: Integrating arithmetic and algebra in elementary school. Portsmouth, $\mathrm{NH}$ : Heinemann.

Case, R., \& Okamoto, Y. (1996). The role of central conceptual structures in the development of children's thought. Monographs of the Society for Research in Child Development, 61, (1-2, Serial No. 246). Chicago: University of Chicago Press.

Cobb, P., Woods, T., \& Yackel, E. (1993). Discourse, mathematical thinking, and classroom practice. In N. Minick, E. Forman, \& A. Stone (Eds.), Education and mind: Institutional, social and developmental processes (pp. 91-119). New York: Oxford University Press.

Cooper, M., \& Sakane, H. (1986). Comparative experimental study of children's strategies with deriving a mathematical law. Proceedings of the Tenth International Conference for the Psychology of Mathematics Education. University of London, Institute of Education, London, pp. 410-414.

English, L. D., \& Warren, E. (1998). Introducing the variable through pattern exploration. The Mathematics Teacher, 91(2), 166-171.

Ferrini-Mundy, J., Lappan, G., \& Phillips, E. (1997). Experiences with patterning. In: Teaching Children Mathematics, Algebraic Thinking Focus Issue. Reston, VA: National Council of Teachers of Mathematics. February, 1997, pp. 282-288.

Hurme, T., \& Jarvela, S. (2005). Students' activity in computer-supported collaborative problem solving in mathematics. International Journal of Computers for Mathematical Learning, 10, 49-73.

Knowledge Building and Mathematics: Shifting the Responsibility for Knowledge Advancement and Engagement 
Jacobs, K., Hiebert, J., Bogard Givvin, K., Hollingsworth, H., Garnier, H., \& Wearne, D. (2006). Does eighth-grade mathematics teaching in the United States align with the NCTM Standards? Results from the TIMSS 1995 and 1999 video studies. Journal for Research in Mathematics Education, 37(1), 5-32.

Kieran, C. (1992). The learning and teaching of school algebra. In D.A. Grouws (Ed.), The handbook of research on mathematics teaching and learning (pp. 390-419). New York: Macmillan.

Kilpatrick, J., Swafford., J., \& Findell, B. (Eds.) (2001). Adding it up: Helping children learn mathematics. Mathematics Learning Study Committee: National Research Council.

Lampert, M. (1990). When the problem is not the question and the solution is not the answer: Mathematical knowing and teaching. American Educational Research Journal, 27(1), 29-63.

Lampert, M., Rittenhouse, P., \& Crumbaugh, C. (1998). Agreeing to disagree: Developing sociable mathematical discourse. In D. Olson \& N. Torrance (Eds.) The Handbook of Education and Human Development (pp. 731-763). UK: Blackwell.

Lannin, J. K. (2005). Generalization and justification: The challenge of introducing algebraic reasoning through pattern activities. Mathematical Thinking and Learning, 7(3), 231-258.

Lee, L. (1996). An initiation into algebraic culture through generalization activities. In N. Bednarz, C. Kieran, \& L. Lee (Eds.), Approaches to algebra: Perspectives for research and teaching (pp. 65-86). Dordrecht: Kluwer Academic Publishers.

Lee, L., \& Wheeler, D. (1987). Algebraic thinking in high school students: Their conceptions of generalisation and justification, Research Report, Concordia University, Montreal, Canada.

MacKinnon, G., \& Aylward, M.L. (2009). Models for building knowledge in a technologyrich setting: Teacher education. Canadian Journal of Learning and Technology, 35(1), Online: http://www.cjlt.ca/index.php/cjlt/article/view/518

Mason, J. (1996). Expressing generality and roots of algebra. In N. Bednarz, C. Kieran, \& L. Lee (Eds.), Approaches to Algebra: Perspectives for research and teaching, (pp. 65-86). Dordrecht: Kluwer Academic Publishers.

Mason, J., Graham, A., \& Johnston-Wilder, S. (2005). Developing thinking in algebra. Great Britain: The Open University and Paul Chapman Publishing.

McAuley, A. (2009). Knowledge Building in an aboriginal context. Canadian Journal of Learning and Technology, 35(1), Online: http://www.cjlt.ca/index.php/cjlt/article/view/514

Knowledge Building and Mathematics: Shifting the Responsibility for Knowledge Advancement and Engagement 
Moss, J., \& Beatty, R. (2006a). Computer supported collaborative learning of patterns and generalizing problems in fourth grade. International Journal of Computer Supported Collaborative Learning, 1, 441-465

Moss, J., \& Beatty, R. (July 2006b). Knowledge Building and knowledge forum: Grade 4 student collaborate to solve linear generalizing problems. In J. Navotna, $\mathrm{H}$. Moraova, K. Magdalena, \& N. Stehlikova (Eds.) Proceedings of the Thirtieth Annual Meeting of the International Group for the Psychology of Mathematics Education, Vol. 4. Prague, Czeck Republic.

Moss, J., Beatty, R., Shillolo, G. \& Barkin, S. (2008) What is your theory? What is your rule? Fourth graders build their understanding of patterns and functions on a collaborative database. In C. Greenes (Ed.), The National Council of Teachers of Mathematics 70th Yearbook (2008): Algebra and Algebraic Thinking in School Mathematics, pp. 155-168.

Moss, J., \& Case, R. (1999). Developing children's understanding of rational numbers: A new model and experimental curriculum. Journal for Research in Mathematics Education, 30(2), 122-147, 119.

Moss, J., Donoahue, Z., Eisenband, J., Shapiro, A., \& Macdonald, P. (October 2004). Three grade 2 classrooms participate in a Knowledge Building approach to pattern exploration. In D. McDougall, \& J.A. Ross (Eds.). Proceedings of the Twenty-Sixth Annual Meeting North American Chapter of the International Group for the Psychology of Mathematics Education, Vol. 2. Toronto, Canada.

Moss, J., \& McNab, S. (in press). An approach to geometric and numeric patterning that fosters second grade students' reasoning and generalizing about functions and covariation. In, J. Cai (Ed.), The Development of Algebraic thinking: cognitive, curricular, and instructional perspectives, Advances in Mathematics Education monograph series, Springer.

Nason, R., \& Woodruff, E. (2002). New ways of learning mathematics: Are we ready for it? Proceedings of the International Conference on Computers in Education (ICCE).

National Council of Teachers of Mathematics (2000). Principles and standards for school mathematics. Reston, VA: National Council of Teachers of Mathematics.

Noss, R., Healy, L., \& Hoyles, C. (1997). The construction of mathematical meanings: Connecting the visual with the symbolic. Educational Studies in Mathematics, $33(2), 203-233$.

Ontario Ministry of Education and Training, MOET (2005). The Ontario Curriculum, Grades 1-8: Mathematics, revised. Queen's Printer for Ontario.

Orton, J. (1997). Matchsticks, pattern and generalisation. Education 25(1), 3-13.

Knowledge Building and Mathematics: Shifting the Responsibility for Knowledge Advancement and Engagement 
Orton, A., \& Orton, J. (1994). Students' perception and use of pattern and generalization. In J. P. da Ponto \& J. F. Matos (Eds.), Proceedings of the $18^{\text {th }}$ International Conference for the Psychology of Mathematics Education (Vol. III, pp. 407-414). Lisbon, Portugal: PME Program Committee.

Orton, A., \& Orton, J. (1999). Pattern and the approach to algebra. In A. Orton (Ed.), Pattern in the Teaching and Learning of Mathematics (pp. 104-120). London: Cassell.

Pimm, D. (1995). Symbols and meanings in school mathematics. London: Routledge.

Pugalee, D. K. (2001). Writing, mathematics, and metacognition: Looking for connections through students' work in mathematical problem solving. School Science and Mathematics, 101(5), 236-245.

Radford, L. (1999). The rhetoric of generalization. In O. Zaslavsky (Ed.), Proceedings of the $23^{\text {rd }}$ Conference of the International Group for the Psychology of Mathematics Education, (Vol. 4, pp. 89-96). Haifa: Technion-Israel Institute of Technology.

Radford, L. (2003). Gestures, speech, and the sprouting of signs: A semiotic-cultural approach to students' types of generalization. Mathematical Thinking and Learning, 5(1), 37-70.

Radford, L. (2006). Algebraic thinking and the generalization of patterns: A semiotic perspective. In S. Alatorre, J. L. Cortina, M. Saiz, \& A. Mendez (Eds.). Proceedings of the 28th annual meeting of the North American chapter of the international group for the psychology of mathematics education (Vol. 1, pp. 2,Äi21). Merida, Mexico: Universidad Pedagogica Nacional.

Resendes, M., \& Chuy, M. (2010, June). Knowledge Building for historical reasoning in Grade 4. Poster presented at the International Conference of the Learning Sciences (ICLS), Chicago, USA.

Scardamalia, M. (2002). Collective cognitive responsibility for the advancement of knowledge. In B. Smith (Ed.), Liberal education in a knowledge society (pp. 67-98). Chicago, IL: Open Court.

Scardamalia, M. (2004). CSILE/Knowledge Forum. In A. Kovalchick, \& K. Dawson (Eds.), Education and technology: An encyclopedia (pp. 183-192). Santa Barbara, CA: ABCCLIO, Inc.

Scardamalia, M. (2003). Knowledge Forum (Advances beyond CSILE). Journal of Distance Education, 17 (Suppl. 3, Learning Technology Innovation in Canada), 2328.

Knowledge Building and Mathematics: Shifting the Responsibility for Knowledge 
Scardamalia, M., \& Bereiter, C. (2007). "Fostering communities of learners" and "Knowledge Building": An interrupted dialogue. In J. C. Campione, K. E. Metz, \& A. S. Palincsar (Eds.), Children's learning in the laboratory and in the classroom: Essays in honor of Ann Brown (pp.197-212). Mahwah, NJ: Erlbaum.

Scardamalia, M., \& Bereiter, C. (2010). A brief history of Knowledge Building. Canadian Journal of Learning and Technology, 36(1).

Scardamalia, M., Bereiter, C., Chuy, M., Prinsen, F., Resendes, M., \& Teplovs, C. (2010). Understanding the nature of science and scientific progress: A theory-building approach. Research Report. Ottawa: Canadian Council of Learning (CCL). Available online at http://www.cclcca.ca/CCL/Research/FundedResearch/201008ScardamaliaScience.html

Scardamalia, M., Bereiter, C., Hewitt, J., \& Webb, J. (1996). Constructive learning from texts in biology. In K. M. Fischer, \& M. Kirby (Eds.), Relations and biology learning: The acquisition and use of knowledge structures in biology (pp. 44-64) Berlin: Springer-Verlag.

Schliemann, A. D., Carraher, D. W., \& Brizuela, B. M. (2001). When tables become function tables. Proceedings of the XXV Conference of the International Group for the Psychology of Mathematics Education, Utrecht, The Netherlands, Vol. 4, 145152.

Sfard, A. (1995). The development of algebra: Confronting historical and psychological perspective. Journal of Mathematical Behavior, 12, 353-383.

Stacey, K. (1989). Finding and using patterns in linear generalizing problems. Educational Studies in Mathematics, 20(2), 147-164.

Stacey, K., \& MacGregor, M. (1999). Taking the algebraic thinking out of algebra. Mathematics Education Research Journal, 11(1), 25-38.

Steele, D. (2005). Using writing to access students' schemata knowledge for algebraic thinking. School Science and Mathematics, 105(3), 142-154.

Steele, D., \& Johanning, D. (2004). A schematic-theoretic view of problem solving and development of algebraic thinking. Educational Studies in Mathematics, 57(1), 6590.

Steen, L.A. (1988). The science of patterns. Science, 240, 611-16.

Sun, Y., Zhang, J., \& Scardamalia, M. (2010). Developing deep understanding and literacy while addressing a gender-based literacy gap. Canadian Journal of Learning and Technology, 36(1).

Knowledge Building and Mathematics: Shifting the Responsibility for Knowledge Advancement and Engagement 
Warren, E. (2000). Visualisation and the development of early understanding in algebra. In M.v. d. Heuvel-Penhuizen (Ed.), Proceedings of the 24th Conference of the International Group for the Psychology of Mathematics Education (Vol. 4, pp. 273-280). Hiroshima.

Warren, E. (2004). Generalizing arithmetic: Supporting the process in the early years. In M. J. Høines \& A. B. Fuglestad (Eds.), Proceedings of the 28th Conference of the International Group for the Psychology of Mathematics Education (Vol. 4, pp. 417424). Bergen, Norway: PME.

Warren, E. (2005). Young children's ability to generalise the pattern rule for growing patterns. In H. L. Chick \& J. L. Vincent (Eds.), Proceedings of the 29th Conference of the International Group for the Psychology of Mathematics Education (Vol. 4, pp. 305-312). Melbourne: PME.

Zazkis, R., \& Liljedahl, P. (2002). Generalization of patterns: The tension between algebraic thinking and algebraic notation. Educational Studies in Mathematics, 49, 379-402.

Zhang, J., Scardamalia, M., Reeve, R., \& Messina, R. (2009). Designs for collective cognitive responsibility in Knowledge Building communities. The Journal of the Learning Sciences, 18, 7-44.

Knowledge Building and Mathematics: Shifting the Responsibility for Knowledge 


\section{Appendix - Generalizing Problems Posted on Knowledge Forum}

\section{Cube Sticker Problem}

A company makes coloured rods by joining cubes in a row and using a sticker machine to put "smiley" stickers on the rods. The machine places exactly 1 sticker on each exposed face of each cube. Every exposed face of each cube has to have a sticker. This rod of length 2 ( 2 cubes) would need 10 stickers.

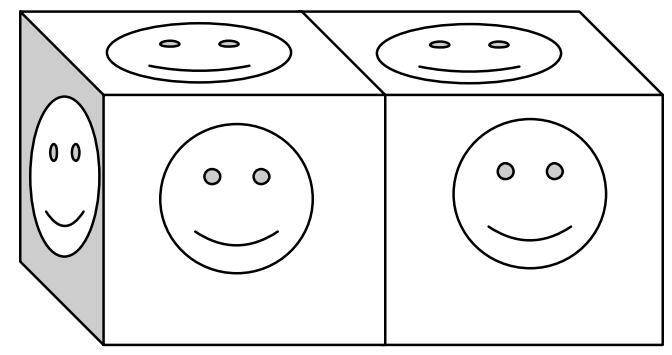

How many stickers would you need for:

A rod of 1 cube

A rod of 2 cubes

A rod of 3 cubes

A rod of 4 cubes

A rod of 10 cubes

How many stickers would you need for a rod of 20 cubes?

How many stickers would you need for a rod of 56 cubes?

What's the rule?

Knowledge Building and Mathematics: Shifting the Responsibility for Knowledge 


\section{Table and Chairs Problem}

Grenvale Public School has decided to include a lunchroom as part of the school's renovations. Mrs. Chen, the principal, found an amazing sale on trapezoid shaped tables so she decided to buy many of these tables for the new lunchroom.

While Mrs. Chen was waiting for her order to be delivered she thought she would draw a plan for her lunchroom. Mrs. Chen decided she would place the chairs around the table so that 2 chairs will go on the long side of the trapezoid and one chair on every other side of the table.

This way 5 students can sit around 1 table.

Then she found she could join 2 tables like this:

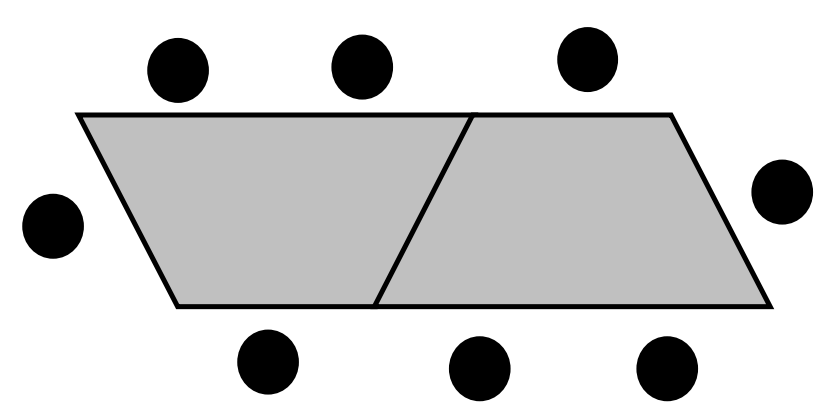

Now 8 students can sit around 2 tables.

How many students can sit around 3 tables joined this way?

How many students can sit around 56 tables?

What is the rule? 


\section{Border Problem}

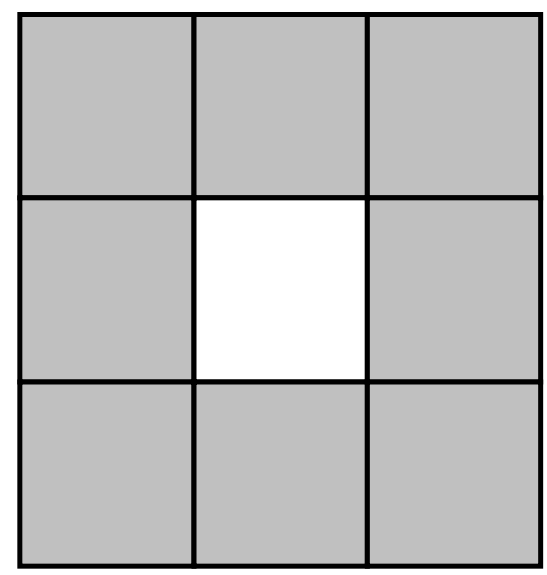

This is a $3 \times 3$ grid of squares with only the outside edge shaded.

If you had a $5 \times 5$ grid of squares where only the outside edge of squares is shaded, how many squares would be shaded?

If you had a $17 \times 17$ grid of squares with only the outside edge of squares shaded, how many squares would be shaded?

If you had a grid of $100 \times 100$ squares, how many would be shaded?

What is the rule?

Knowledge Building and Mathematics: Shifting the Responsibility for Knowledge 


\section{Triangle Dot Problem}

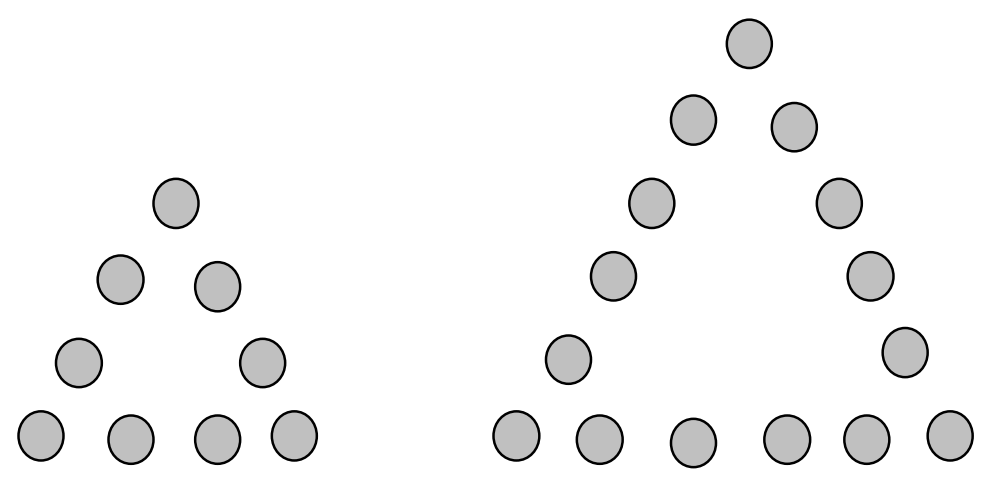

Above is a 4 dot triangle where each side has 4 dots. It is made using a total of 9 dots.

The next triangle is a 6 dot triangle. It has a total of 15 dots.

How many dots would you need altogether for a 16 dot triangle?

How many dots would you need altogether for a 100 dot triangle?

Is there a rule?

Knowledge Building and Mathematics: Shifting the Responsibility for Knowledge 


\section{Pattern Kingdom}

In the Pattern Kingdom, each city is connected to the other cities by a road. To make it simple for people to get around, there is a road connecting each city with all of the other cities. When the Pattern Kingdom only had 3 cities, there were 3 roads to connect them.

When the Pattern Kingdom grew to 4 cities, there were 6 roads to connect them so that there was a direct route from any city to any other city.

Now the Pattern Kingdom has 14 cities. How many roads does it have?

What if there were 32 cities? How many roads would there be?

Is there a rule?

\section{Handshake Problem}

Imagine that the Maple Leafs won the Stanley Cup and you are at a huge party with everyone in Toronto to celebrate.

Everyone starts to shake hands with other people who are there.

If 2 people shake hands there is 1 handshake.

If 3 people are in a group and they each shake hands with the other people in the group, there are 3 handshakes.

If 4 people are in a group and they each shake hands with the other people in the group, there are 6 handshakes.

How many handshakes would there be if there were 10 people in the group?

How many handshakes would there be if there were 100 people in the group?

Can you use a rule to help you figure this out?

Knowledge Building and Mathematics: Shifting the Responsibility for Knowledge 